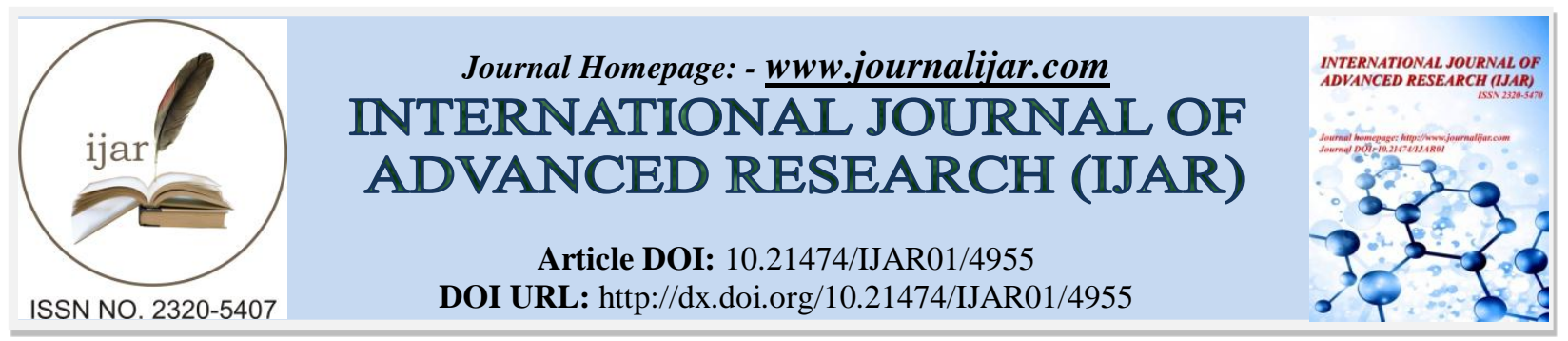

RESEARCH ARTICLE

\title{
PERCEPTION TOWARDS TRAINING PROGRAMME : A STUDY AMONG THE OFFICERS OF INDIAN OVERSEAS BANK.
}

\author{
K. Iyyapparajan ${ }^{1}$ and Dr. P. Chinnadurai ${ }^{2}$. \\ 1. Asst. Professor, Department of Business Administration Annamalai University, Annamalai Nagar, Tamil Nadu, \\ India. \\ 2. Asst. Professor, Manangement wing, DDE. Annamali University, Annamalai Nagar, Tamil Nadu, India.
}

\section{Manuscript Info}

Manuscript History

Received: 25 May 2017

Final Accepted: 27 June 2017

Published: July 2017

Key words:-

Bank officers, Employee

turnover,Perception, Training

\section{Abstract}

The level of knowledge and skills of the existing manpower and their level of commitment towards achieving corporate goals is the measure of critical distinctive competence of a firm. According to Thang (2009) human resource capital is a basic source to achieve competitive advantage. Human capital is neither duplicated nor bought in the market. Training can provide abilities, knowledge and skills that enhance individual performance and it ultimately leads towards organisational performance. Inadequate training policy may frustrate employees from meeting job expectations and encourage them to look for alternatives that foster employee development and success. In this connection, a research study has been undertaken to study the perception of the IOB officers towards training programmes offered by their bank. The research are discussed here.

Copy Right, IJAR, 2017,. All rights reserved.

\section{Introduction:-}

The level of knowledge and skills of the existing manpower and their level of commitment towards achieving corporate goals is the measure of critical distinctive competence of a firm. According to Thang (2009) human resource capital is a basic source to achieve competitive advantage. Human capital is neither duplicated nor bought in the market. Training can provide abilities, knowledge and skills that enhance individual performance and it ultimately leads towards organisational performance.

Prominent business leaders acknowledge that human resources are to be more carefully nurtured than ever before, just as with any other capital resources of a firm. Senyucel's (2009) sees HRM as a combination of people-centered management practices that recognise employees as assets and are geared towards creating and maintaining a skilful and committed workforce for achieving organisational goals. Contemporary progressive business philosophy advises that the expenditure of the employees' salary sheet should be considered an investment rather than a cost. From that point of view the rate of employee turnover is a good indicator of sustained business growth. Inadequate training policy may frustrate employees from meeting job expectations and encourage them to look for alternatives that foster employee development and success. According to the American Society for Training and Development, (ASTD) "41\% of employees at companies with inadequate training programs plan to leave within a year, versus $12 \%$ of employees at companies who provide excellent training and professional development programs."

Corresponding Author:- K. Iyyapparajan.

Address:- Asst. Professor, Department of Business Administration Annamalai University, Annamalai 
As per IOB annual report (2015-2016) statistics there is a total of 3700 branches in the year of 2015 the operating income was 2885 Crores. The total Employee strength is 31846 and the total asset of IOB 274,436.76 Crores, the total deposits around 2,13,319 Crores. Considering the significant role of the IOB in the economy as well as maintaining its operational efficiency, an effective employee training program is inevitable. Failure or underperformance of an individual bank may create a serious disorder in the economy.

\section{Objectives Of The Study:-}

* To know the perception of the respondents on training and development measures.

* To find out the effectiveness of training and development programmes among the IOB officers.

* To provide suggestions for better ways and means to improve the training and development programme.

\section{Literature Review:-}

Ahmad and Bakar (2003) suggest that employees who recognise the benefits of training tend to be more committed and so be more willing to participate in an organisation's training activities. Barrett \& O'Connell (2001) emphasised the importance of effective training for organisational success. They realised the importance of employees training in the workplace as training gives the impression of care and importance of employees, so they will be loyal to the organisation. Organisations that invest in training give the feeling of values and employees will be less interested in quitting.

Prakash R. Pillai (2008) attempted to analyze the influence of the human resource development climate existing in banks on the learning orientation of the bank employees. Capable employees are the greatest assets of all organization. The proficiency of employees plays an essential role in the context of the diverse challenges faced by the contemporary organizations. Talent management, employee engagement and employee retention have become the key concerns of HRD professionals. This is of greater relevance in the banking organizations, being a highly HR intensive sector. In order to maintain and develop their competencies, the employees should have an open mind for learning and change. This proactive approach can be generated by providing adequate opportunities as well as motivation for the employees by fostering a supportive and favorable climate for learning in organizations.

Al-Emadi and Marquardt (2007) examined the perceptions of senior staff in the Qatari petrochemical industry on the perceived benefits of training participation and its impact on organisational commitment. They found a positive relationship between perceived training benefits and both effective and continuous commitment. Oguntimehin (2005) emphasized the usefulness of training in the organisation. He identified the functions of training as follows: increases productivity, improves the quality of work; improves skills, knowledge, understanding and attitude; enhances the use of tools and machinery, reduces waste, Accidents, turnover, lateness, absenteeism and other overhead costs, eliminates obsolescence in skills, technologies, methods, products, capital management etc. The primary goal of many employee development programs is to communicate the vision of the organisation, help workers understand the corporate values and culture, and show employees at every level how they can help the company succeed (Gerbman, 2006). Some companies have found that new employee orientation is a key to success, so they are spreading it out over several months so that employees understand the company, its products, its culture, its policies, and its competition (Kleiman, 2002). There are also companies that require a certain number of training hours for every employee at every level of the organisation so that everyone knows their role in carrying out the corporate mission (Wilson, 2005). A truly effective employee development program should include learning, career planning, goal setting, and evaluation. These areas will help the program benefit the employees who utilise it and the organisation that provides it. Without them, the employee development reverts back to being simply training (Petrecca 2000). According to Dobbs (2003), knowledge is capital for both the individual worker and the company. Organisations and individuals should value knowledge as they do money, because in today's market they go hand in hand. Some organisations fear that career planning will communicate to employees that their jobs are at risk, but it can be framed differently to communicate that they are willing to invest in helping employees reach their potential (Moses, 2000). This fear can be removed if the training helps to create an optimal career plan for the employee. Logan (2004) suggests that the purpose of career planning as part of an employee development program is not only to help employees feel like their employers are investing in them, but also help people manage the many aspects of their lives and deal with the fact that there is not a clear promotion track. Cunniff (2005) affirms that employers can no longer promise job security, but they can help people maintain the skills they need to remain viable in the job market. 
Srimannarayana M. (2011) in his study found that Training and Development is very important component in the modern Human Resource Management and the scope of training and development vary from one organization to another. The present study is based on primary data. Data is collected from 105 HR/Training professionals working in manufacturing, IT/ITES and service sector with a minimum experience of three year in their respective organization in the functional area of training and development. The study revealed that more than $75 \%$ of respondents have believed that performance improvements made because of training is an extremely valuable measure and $70.48 \%$ have believed that transfer of learning is extremely important. Almost (95.24\%) respondents have mentioned that they collect feedback of the participants after completion of the training programme routinely. There is a gap between the measures that that are used actually in assessing training and development and HR/Training professionals do not have control over data that is required for measuring training and development.

Purohit (2012) studied the existing policies practiced in co-operative banks to appraise the level of HRD practices, to assess the satisfaction level of employees about HRD practices particularly Training and development \& Reward and recognition of employees. In the present study structured questionnaire via in-depth personal interviews is used to collect primary data. From large number of banks in Pune region 16 are selected for the study. Information was collected from 30 employees of different level. The study adopted random sampling with regard to the selection of cooperative banks. The study revealed that training helps employees to gain better understanding in the area of Job and this will enhance their stock of knowledge. Extensive training providing the continuous development, such as on-the-job training, training programmes and workshops can be a driving factor for the activities in the firm. The present paper also suggests the ways \& means by which the selected co-operative banks can improve their high performances of work practices.

\section{Methodology:-}

An empirical study has been conducted to identify different dimensions of training and development programs of the banks, such as number of programs provided, types of training methods, length of program, training place and layout, skill and knowledge of trainers, statement of training objective and content to the trainees, application of learning from training to the work place. This study is based on both primary and secondary data and the research covers the entry- and mid-level executives from different branches of IOB in Tamilnadu.

Duration of this study was twenty (20) working days and five (5) respondents were carefully contacted and interviewed face to face in each day in order to collect their opinion. Secondary data were collected from internet, articles from different journals, training manuals, annual report of INDIAN OVERSEAS BANK. Generated data from the survey were processed with the help of SPSS and MS-Excel.

\section{Results and Discussion:-}

INDIAN OVERSEAS BANK provides different types of training programs for development of professional skills of employees. Generally, banks arrange on- the-job training, job rotation, coaching or understudy approach, action learning, Fitch training, etc. From the analysis, the weighted averages of all variables have been calculated separately. From the mean, the variables acceptability on the basis of training standard have been found and with hypothesis testing it can be easily understood the acceptability of training variables by the employees.

Table 1:- Perception on adequate number of training programs for the officers

\begin{tabular}{|c|c|c|c|c|c|c|}
\hline Response $\rightarrow$ & Strongly Agree & Agree & Neutral & Disagree & Strongly Disagree & Total \\
\hline Frequency & 30 & $\mathbf{2 7}$ & 18 & $\mathbf{1 7}$ & $\mathbf{8}$ & 100 \\
\hline Point & 5 & 4 & 3 & 2 & 1 & \\
\hline Outcome & 150 & $\mathbf{1 0 8}$ & 54 & $\mathbf{3 4}$ & $\mathbf{8}$ & 354 \\
\hline
\end{tabular}

Outcome $=$ Frequency $($ Survey Figure $) \times$ Point Assigned

Weighted Average $=$ Total Outcome/Sample Size $=354 / 100=3.54$

In the above findings, it has been found that out of 100 respondents 30 respondents strongly agreed and 8 strongly disagreed about the adequate training programs for employees. The weighted average value is 3.54 which is higher than optimum level 3.50. So the bank needs to arrange an adequate number of training program for employees taking into consideration the level of knowledge and skill of each officers. 
Table 2:- Perception on Training objective and content is adequately explained much ahead of the training program

\begin{tabular}{|c|c|c|c|c|c|c|}
\hline Response $\rightarrow$ & Strongly Agree & Agree & Neutral & Disagree & Strongly Disagree & Total \\
\hline Frequency & 31 & 26 & 29 & 11 & 03 & 100 \\
\hline Point & 5 & 4 & 3 & 2 & 1 & \\
\hline Outcome & 155 & 104 & 87 & 22 & 03 & 371 \\
\hline
\end{tabular}

Outcome $=$ Frequency $($ Survey Figure $) \times$ Point Assigned

Weighted Average $=$ Total Outcome/Sample Size $=371 / 100=3.71$

The interview with the bank employees revealed that out of 100 respondents, 31 strongly agreed about the clarification of the training objective and content. The weighted average value is 3.71 , which is satisfactory.

Table 3:- Training materials and resources are resource worthy for better learning

\begin{tabular}{|c|c|c|c|c|c|c|}
\hline Response $\rightarrow$ & Strongly Agree & Agree & Neutral & Disagree & Strongly Disagree & Total \\
\hline Frequency & 30 & 24 & 21 & 18 & 07 & 100 \\
\hline Point & 5 & 4 & 3 & 2 & 1 & \\
\hline Outcome & 150 & 96 & 63 & 36 & 07 & 357 \\
\hline
\end{tabular}

Outcome $=$ Frequency $($ Survey Figure $) \times$ Point Assigned

Weighted Average $=$ Total Outcome $/$ Sample Size $=357 / 100=3.57$

The respondents were asked whether the bank provides resource worthy materials, tools and techniques for training programs, 30 respondents gave strongly agreed opinion with weighted average value 3.57 which is to some extent higher than the expected level. Though respondents are satisfied about the materials, tools and techniques of training programs, the bank should give more priority to providing highly outstanding materials for training programs.

Table 4:- Perception on Varied training methods are available for necessary learning

\begin{tabular}{|c|c|c|c|c|c|c|}
\hline Response $\rightarrow$ & Strongly Agree & Agree & Neutral & Disagree & Strongly Disagree & Total \\
\hline Frequency & 26 & 36 & 18 & 09 & 11 & 100 \\
\hline Point & 5 & 4 & 3 & 2 & 1 & \\
\hline Outcome & 130 & 144 & 54 & 18 & 11 & 357 \\
\hline
\end{tabular}

Outcome $=$ Frequency $($ Survey Figure $) \times$ Point Assigned

Weighted Average $=$ Total Outcome/Sample Size $=357 / 100=3.57$

From the analysis it is noted that 28 respondents strongly agree with the statement that varied training methods are available for necessary skill development of employees; whereas 8 respondents strongly disagree with this statement with a weighted average value 3.57 lying between the agree and neutral position. Banks should keep existing varieties of training methods for skill development.

Table 5:- Perception on suitable for learning.

\begin{tabular}{|c|c|c|c|c|c|c|}
\hline Response $\rightarrow$ & Strongly Agree & Agree & Neutral & Disagree & Strongly Disagree & Total \\
\hline Frequency & 28 & 26 & 24 & 08 & 14 & 100 \\
\hline Point & 5 & 4 & 3 & 2 & 1 & \\
\hline Outcome & 140 & 104 & 72 & 16 & 14 & 346 \\
\hline
\end{tabular}

Outcome $=$ Frequency $($ Survey Figure $) \times$ Point Assigned

Weighted Average $=$ Total Outcome/Sample Size $=346 / 100=3.46$

It is shown from the above analysis that among 100 respondents only 28 respondents are strongly agreed about the period of training program where weighted average value stands at 3.46. And the value is lower than the optimum level of satisfaction. So, the bank should consider the period of training program effectively.

Table 6:- Perception on environment of the training location are suitable for better learning

\begin{tabular}{|c|c|c|c|c|c|c|}
\hline Response $\rightarrow$ & Strongly Agree & Agree & Neutral & Disagree & Strongly Disagree & Total \\
\hline Frequency & 26 & 33 & 18 & 16 & 07 & 100 \\
\hline Point & 5 & 4 & 3 & 2 & 1 & \\
\hline Outcome & 130 & 132 & 54 & 32 & 07 & 355 \\
\hline
\end{tabular}

Outcome $=$ Frequency $($ Survey Figure $) \times$ Point Assigned 
Weighted Average $=$ Total Outcome $/$ Sample Size $=355 / 100=3.55$

It is observed from the above analysis that out of 100 respondents 26 have given their strong positive answer regarding training place and layout which has led the employees to have knowledge from the training program effectively. But a considerable portion of respondents have neutral thinking regarding this issue which calculates weighted average value 3.55. This indicates that the existing layout and physical environment of the training centre should continue with due care.

Table 7:- Perception on sufficient skill and knowledge about the contents of the training programs.

\begin{tabular}{|c|c|c|c|c|c|c|}
\hline Response $\rightarrow$ & Strongly Agree & Agree & Neutral & Disagree & Strongly Disagree & Total \\
\hline Frequency & 26 & 29 & 24 & 18 & 3 & 100 \\
\hline Point & 5 & 4 & 3 & 2 & 1 & \\
\hline Outcome & 130 & 116 & 72 & 36 & 3 & 357 \\
\hline
\end{tabular}

Outcome $=$ Frequency $($ Survey Figure $) \times$ Point Assigned

Weighted Average $=$ Total Outcome $/$ Sample Size $=357 / 100=3.57$

It is found from the above analysis that out of 100 respondents, 26 respondents have strongly agreed that training instructors have adequate knowledge and skill about training program and a significant portion (24 respondents) have neutral opinion regarding this issue. Sometimes training instructors are unable to explain issues as expected by the participants. The weighted average value is 3.57 , which is to the optimum level.

Table 8:- Perception on learning from the training program into workplace.

\begin{tabular}{|c|c|c|c|c|c|c|}
\hline Response $\rightarrow$ & Strongly Agree & Agree & Neutral & Disagree & Strongly Disagree & Total \\
\hline Frequency & 30 & 40 & 20 & 08 & 02 & 100 \\
\hline Point & 5 & 4 & 3 & 2 & 1 & \\
\hline Outcome & 150 & 160 & 60 & 16 & 03 & 388 \\
\hline
\end{tabular}

Outcome $=$ Frequency $($ Survey Figure $) \times$ Point Assigned

Weighted Average $=$ Total Outcome $/$ Sample Size $=388 / 100=3.88$

From the above analysis, researchers discovered that out of 100 respondents, 30 respondents are strongly agreed and opined that employees can apply learning from training program to the practical work in the bank; whereas only two respondents said that employees cannot apply knowledge, earned from the training program, to the practical field. The weighted average value is 3.88 , which is higher than the expected level.

\section{Recommendation:-}

In light of these findings, researchers are inclined to suggest some guidelines to improve the training and management development programs for organisational success in the research areas:

1. Training objectives and contents should be communicated to the designated participants well ahead so that they can prepare themselves by avoiding ambiguity about the goal of the training program. It also helps them become more motivated and active in participation.

2. Training methods should be tailored to the trainees' need so that the intended knowledge and skills can be conferred in a much more understandable and comfortable manner.

3. Training program organisers should make training materials and manuals available to participants so that they can follow the instructions of the instructor. It also keeps participants more attentive within the program.

4. Training programs should be arranged in an appropriate place where participants will remain free from all social and job related stress. Participant setting layout should be convenient enough for effective communication to be uninterrupted. Training should be arranged when it is necessary as per priority of the training need.

5. In the case of choosing qualified trainers, program designers should consider that trainer's depth of knowledge and length of experience are two of the most important variables that will eventually help to draw attention and confidence of the participants. Moreover, selected trainers must have adequate passion towards their profession..

6. Training departments of banks should provide policy support, so that participants will be encouraged to transform learning into the job. For this reason, a supportive culture is to be nurtured and trickled down to all layers of the organisation where intended transformation will be supported by the superior as well as peer 
groups of the organisation. A reward policy should be designed with the intention of encouraging trainees to transform their learning.

7. Bank must introduce career development policy instead of mere employee selection and recruitment and promotion in the work place.

\section{Conclusion:-}

In the process of globalisation the interdependence of different economies becomes more evident than ever before. The volume of cross national trade and commerce as well as skilled workforce migration has been raised manifold. For that very reason the service of the banking sector is the most acceptable means of transferring funds between the relevant parties in order to expedite international trade. Restructured knowledge for taking competitive decisions, updated skill in order to use state-of-the-art technologies and a flexible attitude towards better organisational responsiveness training is an unremitting requirement. As this research reveals, training objectives are not well communicated beforehand, training methods that are used are ineffective, supplied materials are obsolete, participants perceive that programs are not well organised, and place and layout of the venue is not satisfactory. It also brings to light the fact that the level of knowledge, skills and attitude (KSAs) of the training instructors is not satisfactory. Respondents opined that they have insufficient scope for transferring knowledge into the workplace in the wake of the training program. It has been shown that IOB in Tamilnadu training programmes are aware of arranging training programs and indeed do implement them. However, the quality of these programs are significantly below par. It could be concluded from this research that if this scenario continues then naturally lack of motivation, unacceptable rate of employee turnover and lower productivity would be the consequence. Smoother international business operations, therefore, will falter due to an inefficient banking service.

\section{References:-}

1. Ahmad, K.Z. and Bakar, R.A. (2003) „The Association between Training and Organizational Commitment among

2. White Collar Workers in Malaysia ${ }^{e e}$, International Journal of Training and Development, 7(3): 166-185.

3. Al Emadi, M.A. and Marquardt, M.J. (2007) „Relationship between Employees ${ }^{\text {ee }}$ Beliefs Regarding Training

4. Benefits and Organizational Commitment in a Petroleum Company in the State of Qatar ${ }^{\text {,e }}$ International

5. Journal of Training and Development, 11(1): 49-70.

6. Barrett, A., \& O'Connell, P. J. (2001). Does Training Generally Work? Measuring the Returns. Industrial and Labor Relations Review, 647-662.

7. Gerbman, R. V. (2006, February). Corporate universities 101. HR Magazine, 45 (2), 101-106.

8. Kleiman, M. (2002, January). What happens if you don't train them and they stay? Occupational Health \& Safety, 69 (1), pp. 18, 70.

9. Logan, J. K. (2004, April). Retention tangibles and intangibles: More meaning in work is essential, but good chair massages won't hurt. Training \& Development, 54 (4), 48-50.

10. Moses, B. (2000, June). Give people belief in the future: In these cynical times, HR must assure employees that faith and work can coexist. Workforce, 79 (6), 134-139.

11. Newman, A., Thanacoody, R., \& Hui, W. (2011). The impact of employee perceptions of training on organizational commitment and turnover intentions: a study of multinationals in the Chinese service sector. International Journal of Human Resource Management , 1765-1787.

12. Oguntimehin, A. (2005) "Teacher Effectiveness: Some practical Strategies for Successful implementation of Universal Basic Education in Nigeria" African Journal of Educational Management Vol. 9, No 1 P. 151 - 161

13. Petrecca, L. (2000, May 1). Agencies teach skill building. Advertising Age, 71 (19), 12.

14. Rosenwald, M. (2006, October 15). Working class: More companies are creating corporate universities to help employees sharpen skills and learn new ones. Boston Globe, H1.

15. Senyucel, Z. (2009). Managing Human Resources in the 21st Century. Available at http://www.bookboon.com. Accessed on 23/11/2009.

16. The benefits of training and development. In J. Prior (Ed.). Gower handbook of training and development (2nd ed.). Hampshire, England: Gower Publishing Ltd.

17. Thang, N. N. (2009). Human resource training, organisational strategy and firm performance in emerging

18. economies: the case of Vietnam. Submitted to the Faculty of Economics and Business Administration, Ghent University, in Fulfillment of the Requirements for the Degree of Doctor in Applied Economics, chapter 2.

19. Tharenou, P. (1997). Organisational, Job, and Personal Predictors of Employee Participation in Training and Development. Applied Psychology: An International Review , 111-134. 
20. Wilson, C. (2005, July 26). More companies recognize the impact of learning centers. St. Louis Post-Dispatch, C8.

21. Zenger, J., Ulrich, D., \& Smallwood, N. (2004, March). The new leadership development: It's about results for your company. Now. Training \& Development, 54 (3), 22-27.

22. Prakash R. Pillai, "Influence of HRD Climate on the Learning Orientation of Bank Employees", Indian Journal of Industrial Relations, Vol. 43, No. 3, 2008, pp. 406-418.

23. Purohit Manisha (2012), "An Evaluation of HRD Practices Followed in Co-operative Banks in Pune Region", ACADEMICIA: An International Multidisciplinary Research Journal, Volume 2, Issue 8, pp 186-195.

24. Srimannarayana M. (2011), "Measuring Training and Development", The Indian Journal of Industrial Relations, Vol.47, No.1, pp. 117-125. 